\title{
System Architecture of Data Warehousing with Ontologies to Enhance Digital Entrepreneurs' Competencies for Higher Education
}

\author{
Thanapol Namnual, Prachyanun Nilsook, and Panita Wannapiroon
}

\begin{abstract}
The purposes of the research were 1) to design a system architecture of data warehousing with ontologies to enhance digital entrepreneurs' competencies for higher education and 2) to evaluate the system architecture of data warehousing with ontologies to enhance digital entrepreneurs' competencies for higher education. The research procedure is divided into two phases. The first phase is the development of the system architecture of data warehousing with ontologies to enhance digital entrepreneurs' competencies for higher education design, while the second phase is the evaluation of the architecture by experts. The 5 individuals chosen were experts in the field of Information Technology and higher education chosen by purposive sampling. The data collection tools were the system and the assessment of an appropriate model using a 5-level rating scale. The statistics used in the data analysis were means and standard deviation. The results showed that 1) the system architecture of data warehousing with ontologies to enhance digital entrepreneurs' competencies for higher education consists of 4 tiers a) the data source b) the data warehouse tier c)the ontology-driven framework tier and d) the progression model tier 2) the expert opinions on the system developed were that it was most appropriate.
\end{abstract}

Index Terms-System architecture, data warehousing, ontologies, digital entrepreneurs' competencies, higher education.

\section{INTRODUCTION}

Nowadays the world situation has changed a lot in terms of education, economics, culture and society. Technology fundamentally affects the lives of people in modern times. Technologies such as artificial intelligence, digital twinning, IoT technology [1], augmented and virtual reality [2] are all attracting a great deal of attention. Competition in higher education is intense and serious. Consequently, universities, both state and private, have to accelerate development in terms of academic quality. Higher education institutions in Thailand are required to meet standards that involve developing suitable plans, putting into place technological strategies, and using business analytics tools such as visualization, decision support systems, and knowledge discovery [3]. Information and communication technology (ICT) is a force that has changed many aspects of the way we live. Just as technology is influencing and supporting what is

Manuscript received February 14, 2019; revised April 19, 2019.

The authors are with the Division of Information and Communication Technology for Education, Faculty of Industrial Education, King Mongkut's University of Technology North Bangkok (KMUTNB), Thailand (e-mail: Thanapol.na@gmail.com, panitaw@kmutnb.ac.th). being learned in schools and universities, so too is it supporting changes in the way students are being taught [4]. Universities therefore have to adjust themselves considerably and quickly put into place strategies that can push them to step over the trap. In addition, the development and the supplementation of potential human resource strategies is another factor affecting higher education [5]. The point of the strategy is that Thai citizens need to be fully equipped within the next 20 years by being provided with lifelong learning and skills for 21st Century. The education for the 21st Century places emphasis on enhancing learning skill, designing new learning systems, changing the role of teachers and increasing management effectiveness. This causes universities to adjust, change and develop their organization potential in terms of both teaching and management.

Thailand 4.0, the vision of Thailand's future, makes all sectors intensively aware of the nation's transformation. Thailand 4.0 involves economic infrastructure reform focusing on innovative technology. The 20 year national strategy indicates that the main factors for Thailand's transition is the development of science, technology, research and development, and innovation. The development is for the provision of high value products and services leading to improved competitive capacity and better life quality. The creation of surrounding and supporting factors that enhance this development will help the nation move from a technology buyer to a technology producer and seller. Moreover, Thailand's digital government development plan proposes that technology changes, for instance more intelligent and automatic processing systems, data quantity in huge databases for deep predictive analysis, smaller portable computer or cell phone devices, will affect. Technology changes concern almost every dimension of society, including government work. The government can use such changes to enhance citizen services, general management, policy applications and problem solution. The application of such change will move the government toward digital government. Therefore, it meets the requirements of the 12th Nation Economic and Social Development Plan focusing on government and education digital capacity development. Data warehouse (DW) management is a key element in the decision-making process. A data warehouse is a repository of an organization's electronically-stored data, and is designed to facilitate reporting and analysis [6]. Managing a data warehouse includes the processes of analyzing, extracting, transforming and loading data and metadata. Our interest in 
knowledge management comes from the types of data involved in the decision-making process.

Semantic heterogeneity occurs when the same information is represented by different expressions in various sources (synonyms), or when an expression is used in various sources to represent different information (homonyms). To solve the semantic heterogeneity problem, the use of ontology seems to be essential [7].

The promotion of new entrepreneurs in the digital field digital entrepreneurs - is currently a very hot topic. This is because it focuses on creating a business incorporating digital technology to create products and services based on innovation, merging with business. In addition, promoting small and medium-sized businesses is an important mechanism to drive the country's economic system. Therefore, there is a push for the promotion of digital startups in accordance with the Thailand Strategy Plan as mentioned above. This can be done by focusing on the development of competencies through the actual creation of digital entrepreneurial competency values via the system architecture related to data warehousing with ontologies to enhance digital entrepreneurs' competencies for higher education.

\section{OBJECTIVE}

1) To create a system architecture of data warehousing with ontologies to enhance digital entrepreneurs' competencies for higher education.

2) To evaluate the system architecture.

\section{Methodology}

Phase 1: System architecture design:

- Design the system architecture of data warehousing with ontologies to enhance digital entrepreneurs' competencies for higher education.

- Create an instrument for assessing the appropriateness of the system architecture of data warehousing with ontologies to enhance digital entrepreneurs' competencies for higher education.

Phase 2: Evaluate of the appropriateness of the system architecture of data warehousing with ontologies to enhance digital entrepreneurs' competencies for higher education.

Research Scope

Population, Sample group and variables

Population

- The population consists of experts in the field of information technology and higher education.

Sample Group

- The sample consisted of 5 experts in the field of information technology and higher education, chosen by purposive sampling. They are highly-experienced experts in these fields and have been operating in these fields for at least 5 years.

Variables

- The independent variable is the system architecture of data warehousing with ontologies to enhance digital entrepreneurs' competencies for higher education.
- The dependent variable is the appropriateness of the system architecture of data warehousing with ontologies to enhance digital entrepreneurs' competencies for higher education.

Research Tools and Data Analysis

The research instruments were an evaluation of the system architecture of data warehousing with ontologies to enhance digital entrepreneurs' competencies for higher education.

The data obtained from the experts were collected and analyzed by using the following statistics:

- Arithmetic mean

- Standard deviation

\section{RESULTS}

Phase 1: Results of the Study Related to Theories, Research, and Experts' Opinion. The illustration of results of the system architecture of data warehousing with ontologies to enhance digital entrepreneurs' competencies can be seen in Fig. 1.

\section{A. Data Source}

Internal Data: The original data sources are the existing relational databases, data warehouses or other data systems that produce structured data. In this category, we have information about students, courses, content, research and development, etc. There may be a database operated in the university's business incubator.

External Data: Several sources are beyond the control of the university administration. This includes knowledge gained from lessons learned from successful SMEs and knowledge from the internet and social media.

Personal Data: This information may be in digital or non-digital form. Digital data includes emails, mobile phones, text messages, digital photos, audio materials, video materials, online purchases and credit card usage. Non-digital information can be in the form of documents, paper, handwritten notes, photographs using paper, newspaper cuttings, etc.

\section{B. Data Warehouse}

The data warehouse provides the science, architecture and tools that business executives need to organize, understand and use information for strategic decision making. Data warehousing systems are a convenient tool in today's world that is competitive and has developed rapidly [8]. Data warehouse systems use back-end tools and utilities to populate and refresh their information. These tools and utilities include the following contributory functions:

Data extraction, which typically involves gathers data from multiple, disparate, and external sources. Data cleaning, which detects errors in the data and corrects them when possible.

Data transformation, which converts data from legacy or host form to warehouse form.

Load, which sorts, summarizes, consolidates, computes views, checks integrity, and builds indices and partitions.

Refresh, which broadcast the updates from the data sources to the warehouse. 


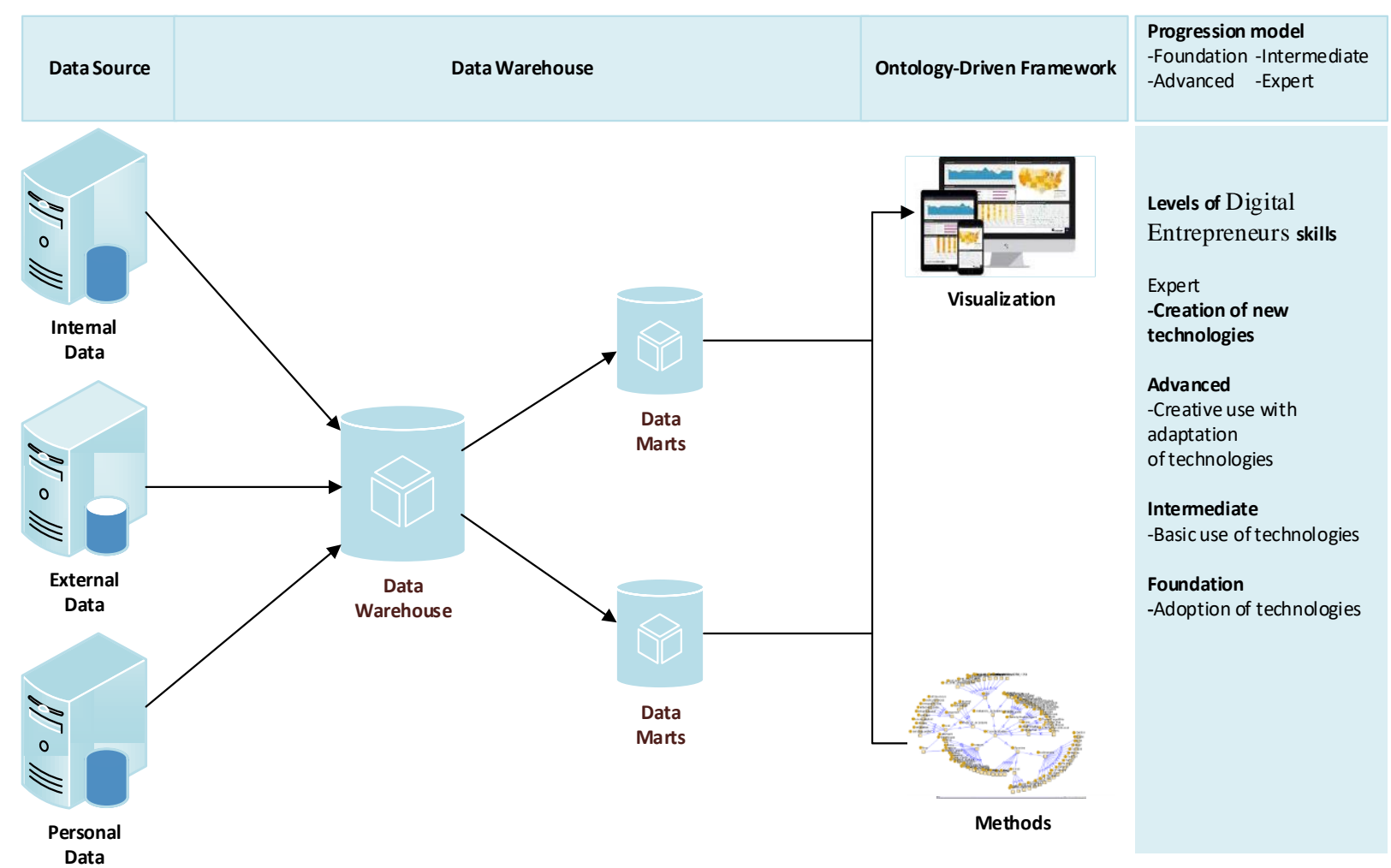

Fig. 1. System architecture of data warehousing with ontologies to enhance digital entrepreneurs' competencies for higher education.

TABLE I: D. PROGRESSION MODEL

Entrepreneurs Progression Model [11]

\begin{tabular}{|c|c|c|c|}
\hline Foundation & Intermediate & Advanced & Expert \\
\hline Relying on support from others & Building independence & Taking responsibility & $\begin{array}{l}\text { Driving transformation, } \\
\text { innovation } \\
\text { and growth }\end{array}$ \\
\hline $\begin{array}{l}\text { Level } 1 \text { Focus on discovering your } \\
\text { qualifications, potentials, interests and } \\
\text { wishes. In addition, the focus is on } \\
\text { recognizing the problems and needs of } \\
\text { various types that can be solved creatively } \\
\text { and develop individual skills and attitudes } \\
\text { [9]. } \\
\text { Level } 2 \text { Focus on exploring different } \\
\text { approaches to solving problems, focusing } \\
\text { on diversity and developing social skills } \\
\text { and attitudes. }\end{array}$ & $\begin{array}{l}\text { Level } 3 \text { Focus on critical } \\
\text { thinking and } \\
\text { experimentation with } \\
\text { creating value, such as } \\
\text { through an entrepreneurial } \\
\text { experience that is useful. } \\
\text { Level } 4 \text { Focus on changing } \\
\text { ideas into action in 'real life' } \\
\text { and responsibility for this. }\end{array}$ & $\begin{array}{l}\text { Level } 5 \text { Focus on } \\
\text { developing your skills for } \\
\text { changing ideas into practice, } \\
\text { increasing responsibility for } \\
\text { creating value, and } \\
\text { developing knowledge } \\
\text { about entrepreneurs. } \\
\text { Level } 6 \text { Focus on working } \\
\text { with others using the } \\
\text { knowledge you need to } \\
\text { create value, cope with more } \\
\text { complex challenges. }\end{array}$ & $\begin{array}{l}\text { Level } 7 \text { Focusing on the } \\
\text { capabilities needed to cope } \\
\text { with complex challenges, } \\
\text { managing the ever-changing } \\
\text { environment with high } \\
\text { uncertainty levels. } \\
\text { Level } 8 \text { Focus on emerging } \\
\text { challenges by developing } \\
\text { new knowledge through } \\
\text { research and development } \\
\text { and innovation capabilities } \\
\text { to achieve excellence. }\end{array}$ \\
\hline \multicolumn{4}{|l|}{ Levels of digital skills [12] } \\
\hline Adoption & Basic or generic use & $\begin{array}{l}\text { Creative use and } \\
\text { adaptations }\end{array}$ & $\begin{array}{l}\text { Creation of new } \\
\text { technologies }\end{array}$ \\
\hline
\end{tabular}

Basic understanding of

technologies, software and applications;

Knowledge of digital rights,

privacy, security and

permanence of data

Ability to make use of information and data,

Famic education and literacy
Famity with technology devices and services ranging from basic issues of

data storage, management,

and organization to make

calculations and

answer questions

Ability to using digital

technologies to collaborate,

communicate and

create
Basic computing skills Familiarity with basic algorithms
Sophisticated knowledge of complex algorithms 


\begin{tabular}{lcc}
\hline \hline & $\overline{\mathrm{x}}$ & $\mathrm{S} . \mathrm{D}$ \\
\hline $\begin{array}{l}\text { System architecture of data warehousing with ontologies to enhance digital } \\
\text { entrepreneurs' competencies for higher education consisted of 4 main tiers } \\
\quad \text { - data source } \\
\quad \text { - data warehouse } \\
\quad \begin{array}{l}\text { - ontology driven framework } \\
\text { - progression mode }\end{array}\end{array}$ & 4.60 & 0.48 \\
\hline $\begin{array}{l}\text { Process of system architecture of data warehousing with ontologies to enhance digital } \\
\text { entrepreneurs' competencies for higher education. }\end{array}$ & 4.40 & 0.48 \\
\hline $\begin{array}{l}\text { Data source tier } \\
\text { Data warehouse tier }\end{array}$ & 4.70 \\
\hline $\begin{array}{l}\text { Ontology driven framework tier } \\
\text { Progression model tier }\end{array}$ & 4.40 \\
\hline $\begin{array}{l}\text { System architecture of data warehousing with ontologies to enhance digital entrepreneurs } \\
\text { competencies for higher education suitability }\end{array}$ & 4.44 \\
\hline Total & 4.50 & 0.45 \\
\hline
\end{tabular}

Data warehouses are really large data stores. All reporting and analysis tools access a single data store. For this reason, many organizations have developed data marts to reduce query workloads. Each data mart is developed for a specific user group. In general, this includes all users with equivalent data requirements. This means that a data mart will have a subset of all data from the data warehouse and often the data warehouse finds that the data query work has decreased [9]. The main advantage of using a data mart only architecture is development speed. When an organization starts from scratch, developing a data mart for a small group of users requires less time than when a data warehouse is developed for a large group of users.

\section{Ontology-Driven Framework}

Methods: To create our OWL ontology we use the "Protégé" platform.

1) Create three classes: DW, Domain, and Resources

2) Export existing domain ontology or create new domain ontology. These ontology concepts may be a subset of the domain class

3) Export the DW conceptual model ontology. To pass from the DW conceptual model to OWL we applied the transformations rules proposed by Prat et al. [10]. Data warehouse concepts are a subset of the DW class

4) Link the concept of DW to the concept of the domain. This task can be automated using existing ontology mapping tools; in this case, we did not consider this option. In order to link the concept of DW to the domain concept, the metaphysics administrator refers to the concept of each data warehouse, the opposite concept, the opposite, etc. in the metaphysical domain.

5) Relate the resources provided by the data warehouse to their corresponding concepts.

Visualization:

1) Input: this is a need expressed with a term or a group of terms.

2) Output: these are concepts related to this need, dealing with resource concepts, domain concepts, and DW structure concepts.

\section{Progression Model}

A progression model involves two major components: 1) entrepreneurs' progression model [11], and 2) levels of digital skills [12]. Table I: D. provides a depiction of the system architecture of data warehousing with ontologies to enhance digital entrepreneurs' competencies for higher education.

Phase 2: Evaluation on the system architecture of data warehousing with ontologies to enhance digital entrepreneurs' competencies for higher education. The results of appropriateness evaluation of system architecture of data warehousing with ontologies to enhance digital entrepreneurs' competencies for higher education is rated as absolutely appropriate overall $(\overline{\mathrm{x}}=4.57, \mathrm{~S} . \mathrm{D} .=0.47)$. The results can be seen in Table I-II.

\section{CONCLUSION}

This paper deals with the system architecture of data warehousing with ontologies to enhance digital entrepreneurs' competencies for higher education. The research procedure was divided into two phases. The first phase deals with the system architecture of data warehousing with ontologies to enhance digital entrepreneurs' competencies for higher education design, while the second phase involves the evaluation of the architecture by experts. The result of the design were the development of four tiers: data source tier, data warehouse tier, ontology driven framework tier and progression model tier. The designed system architecture was examined in terms of its appropriation by 10 experts. The result revealed that the appropriateness of the architecture was found to be at the "Most appropriate level".

In brief, the system architecture of data warehousing with ontologies to enhance digital entrepreneurs' competencies for higher education is the process through which organizations generate value from their intellectual and knowledge-based assets, disseminating this knowledge and sharing it in an effort to enhance digital entrepreneurs' competencies.

As the development of system architecture for this purpose is relatively new and not much has been written on the 
subject, we have tried to provide as much support as possible for the future development of system architecture for this purpose. We have described these changes and hope that our work will add something to the expanding area of system architecture.

\section{ACKNOWLEDGMENT}

This research was funded by the Capacity Building Program for New Researcher 2018 of the National Research Council of Thailand (NRCT).

\section{REFERENCES}

[1] R. Laoha, P. Wannapiroon, and P. Nilsook, "The system architecture of digital activity portfolio via internet of things for digital university," International Journal of Advanced and Applied Sciences, vol. 6, no. 2, pp. 81-86, 2019.

[2] T. Jantakoon, P. Wannapiroon, and N. Nilsook, "Virtual immersive learning environments (VILEs) based on digital storytelling to enhance deeper learning for undergraduate students," Higher Education Studies, vol. 9, no. 1, pp. 145-150, 2019.

[3] T. Jantakoon and P. Wannapiroon, "System architecture of business intelligence to AUN-QA framework for higher education institution," The Turkish Online Journal of Educational Technology, Special Issue for INTE 2017 (November), pp. 1045-1052, 2017.

[4] R. Laoha and P. Piriyasurawong, "The instructional design flipped mastery classroom model using virtual classroom system with problem-based toward problem solving ability," International Journal of e-Education, e-Business, e-Management and e-Learning, vol. 8, no. 1, pp. 18-25, 2018.

[5] J. P. Surej, "The integration of information technology for digital university: A study of faculty's attitude towards IT adoption in the teaching process," Contadina y Administration, vol. 60, pp. 230-252, 2015

[6] W. H. Inmon, "Tech topic: what is a data warehouse? Prism solutions," Data Warehouse Performance, Wiley Publishing, 1995.

[7] E. Mena, A. Illarramendi, and V. Kashyap, Distributed and Parallel Databases, 2000, p. 223.

[8] J. Han, M. Kamber, and J. Pei, "Data warehousing and online analytical processing," Morgan Kaufmann Series in Data Management Systems, Morgan Kaufmann, Boston, pp. 125-185, Data Mining (Third Edition), 2012.
Morgan Kaufmann, Boston, pp. 125-185, Data Mining (Third Edition), 2012.

[9] A. Simon, Chapter 2 - The Role and Charter of the Enterprise Business Intelligence and Data Warehousing Program Manager, Morgan Kaufmann, Boston: Enterprise Business Intelligence and Data Warehousing, pp. 15-27, 2015.

[10] N. Prat, I. Megdiche, and J. Akoka, Multidimensional Models Meet the Semantic Web: Defining and Reasoning on OWL-DL Ontologies for OLAP, Hawaii, USA: DOLAP, 2012.

[11] M. Bacigalupo, P. Kampylis, Y. Punie, and G. Brande, EntreComp: The Entrepreneurship Competence Framework, Luxembourg: Publication Office of the European Union; EUR 27939 EN, 2016.

[12] P. Dimaggio, E. Hargittai, C. Celeste, and S. Shafer, "Digital inequality: From unequal access to differentiated use," Social Inequality, Russell Sage Foundation, pp. 355-400, 2004.

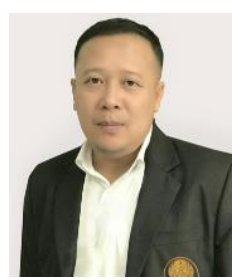

Thanapol Namnual is a Ph.D candidate in the Division of Information and Communication Technology for Education, Faculty of Technical Education, King Mongkut's University of Technology North Bangkok, Thailand.

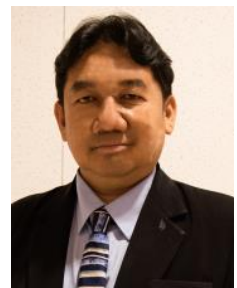

Prachyanun Nilsook is an associate professor at the Division of Information and Communication Technology for Education, Faculty of Technical Education, and Director of Technical Vocational Education Research Center, and Science and Technology Research Institute (STRI), King Mongkut's University of Technology, North Bangkok (KMUTNB), Thailand.

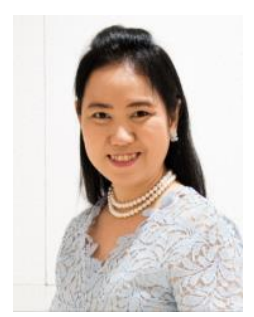

Panita Wannapiroon is an associate professor at the Division of Information and Communication Technology for Education, Faculty of Technical Education, Director of Innovation and Technology Management Research Center (ITMRC), and Science and Technology Research Institute (STRI), King Mongkut's University of Technology, North Bangkok (KMUTNB), Thailand. 